\title{
Preparation and Standardization of Siddhalepa Ayur Elixir 14 Blood Purifier (Nimba arishta), A Traditional Ayurvedic Formulation
}

\section{S Sylvester Darvin, Lankani Hettigoda*, Saumya Perera, Charitha Ekanayake, Vindya Munasinghe and Arthur Bamunuarachi}

Department of Research and Development, Hettigoda Industries (Pvt) Ltd, Ratmalana, Sri Lanka

*Corresponding Author: Lankani Hettigoda, Department of Research and Development, Hettigoda Industries (Pvt) Ltd, Ratmalana, Sri Lanka.

Received: November 12, 2019; Published: November 21, 2019

DOI: $10.31080 /$ ASPS.2019.03.0443

\begin{abstract}
Ayurveda consists of different types of formulations, including fermented varieties, arishtas and asavas. Because of their efficacy, consistency and attractive characteristics, arishtas are regarded as unique and valuable therapies. It was prepared using herbal drug decoction and contains self-generated alcohol. While these formulations are listed in traditional literature and their scientific research and reporting are used regularly, it is important to strengthen Ayurveda on the global market. this research attempt to plan and test Siddhalepa Ayur Elixir 14 Blood Purifier (Nimba arishta) was made. Azadirachta indica is a major component of Nimba arishta and It has been used to treat rashes, fever, rheumatic disorders and helminthiasis; it is also considered as blood-purifier. After fermentation of traditionally prepared Nimba arishta formulations, 8.32 percent w/w alcohol was made. Due to sweet taste combined with fine fragrance, which hides unpleasant taste and odour of added herbal ingredients, it is palatable to use and also has good shelf life. This study standardized a traditional ayurvedic arishata formulation Siddhalepa Ayur Elixir 14 Blood Purifier according to the international standards.
\end{abstract}

Keywords: Ayurveda; Fermented Formulation; Arishta; Siddhalepa Ayur Elixir

\section{Abbreviations}

PCA: Plate Count Agar; WHO: World Health Organisation; CFU: Colony Forming Units; ICH: International Council for Harmonisation; SLS: Sri Lanka Standards

\section{Introduction}

Ayurveda is one of the ancient medicine systems of the world and is being practised over 3000 years [1]. The term 'Ayurveda' consisted of two epithets: Ayu (Life) and Veda (Knowledge). The source of this life science, which is hard to identify, was put somewhere around $6000 \mathrm{BC}$ [2]. Ayurvedic remedies are considered as affordable, safe with no or reduced side effects [3]. This traditional system consists of different types of medicines, including fermented products which are known as arishtas and asavas $\approx \approx$ medicinal wines). Arishtas are made with decoctions of various herbs; while asavas are prepared using fresh herbal juices [4]. They have been prepared by fermenting the herbal decoction or juices in airtight sealed vessels along with the flowers of Woodfordia fruticosa, sugar and occasionally with some other plant powders [5,6]. These are special self-alcohol generated liquid form of ayurvedic drugs [7] having longer shelf life, having wide array of therapeutic values [8] and generally consumed for their perceived prophylactic efficacy.

In Sri Lanka, arishtas one of the widely used ayurvedic form of drugs and they have been used for the treatment of a great variety of diseases [9]. According to ayurvedic philosophy, these alcoholic preparations possess a moderate potency and are therefore they can be useful to treat convalescent phase of a disease; while other forms are useful for the treatment of acute disorders [10,11]. As early as 320 BC Caraka, one of the sages of ayurveda, described 84 varieties of such alcoholic preparations. These preparations were considered to "strengthen the mind, body, the power of digestion, help in overcoming sleeplessness, grief and anorexia" [12].

Azadirachta indica A. Juss (Meliacae), commonly known as Nimba in Sanskrit is being used widely in Ayurveda to treat various illnesses in Sri Lanka [5]. The decoction of the Azadirachta indica barks (Nimbadi quath) is used to prepare Nimba arishta, one of the most commonly used arishtas in Sri Lanka. It has been used to treat rashes, fever, rheumatic disorders and helminthiosis; it is also con- 
sidered as blood-purifier [13]. Siddhalepa is the flagship brand of the Hettigoda Group, Sri Lanka and it produces over 150 ayurvedic health care and cosmetic products. Siddhalepa Ayur Elixir 14 Blood Purifier (SAE-14) is the brand name of nimba arishta produced from Siddhalepa; which has been produced in accordance with ayurvedic pharmacopeia [14]. SAE-14 contains the barks of Azadirachta indica and the fruits of Embelica ribes as main ingredients. Previous reports found that Nimba arishta prepared from Ayurveda Municipal Manufacturing Company exhibited immunomodulatory [15] and anti-inflammatory [5] activities. In this communication, the quality parameters of SAE-14, a branded formulation of Nimba arishta was standardized using Ayurvedic Pharmacopeia and international standardization methods.

\section{Methodology}

Instrumentation and chemicals

All the analyses were done using following instrumentations. pH was analyzed on a pH meter Thermo-scientific (STAR A214). Refractive index and sugar content were analyzed on Rose Scientific Refractometer. Alcohol content was evaluated on ebulliometer. Specific gravity was estimated using specific gravity bottle. All the culture media were obtained from OXIOD and Lab M UK. All the reagents and chemicals obtained from Sigma at analytical grade.

\section{Plant materials}

Azadirachta indica barks, dried fruits of Embelia ribes and cane sugar were procured from local market, and their botanical identity was authenticated by R. A. S. W. Ransinghe, Botanist of the National Herbarium of Peradeniya, Sri Lanka. Voucher specimens of the plant materials were deposited in the herbarium at Department of Research and Development, Hettigoda Industries (Pvt) Ltd, 33/3, Sri Dharmarama Road, Ratmalana, Sri Lanka for future reference.

\section{Preparation of SAE-14}

SAE-14 was prepared in accordance with the method given in ayurveda pharmacopeia [14]. The list of ingredients is given in table 1. The raw drug materials were cleaned, washed and dried before their usage.

\begin{tabular}{|l|c|}
\hline Ingredients & Quantity \\
\hline Azadirachta indica & $102 \mathrm{Kg}$ \\
\hline Embelia ribes & $5.5 \mathrm{Kg}$ \\
\hline Cane sugar & $310 \mathrm{Kg}$ \\
\hline Water & $4014 \mathrm{l}$ \\
\hline
\end{tabular}

Table 1: Composition of Siddhalepa Ayur Elixir 14 Blood Purifier (SAE-14).

\section{Preparation of decoction}

The barks of Azadirachta indica and fruits of Embelia ribes were pulverized and sieved with no. 44 sieve. This powder was mixed with required amount of potable water and boiled under mild heating till the final volume was reduced to one eight of its initial volume. The decoction was filtered through muslin cloth and filtrate was used for further processing [14].

\section{Fermentation}

Required quantity of cane sugar was dissolved in decoction by stirring and filtered through muslin cloth. Filtrate was collected in clean porcelain jar and the container was sealed with mud smeared cloth and kept in clean and dry room for fermentation. After fermentation the fermented material is filtered through muslin cloth. Filtrate was packed in air tight container and used for evaluation [14].

Physicochemical evaluations

Preliminary evaluation

Evaluation of organoleptic characteristics viz. odour, taste, and colour of SAE-14 was carried out using standard methods [16].

Estimation of alcohol content

$50 \mathrm{~mL}$ of SAE-14 was taken for the ebulliometer estimations. After 1:1 dilution with distilled water, $50 \mathrm{~mL}$ of the working solution was kept into the boiling chamber. The temperature was read at the lowest constant boiling point. Distilled water was used as the blank and the percentage of alcohol was read from the scale $[16,17]$

\section{Estimation of specific gravity}

Specific gravity of SAE-14 was determined according to the method of British Pharmacopoeia [17]. The mass of empty specific gravity bottle was measured initially [(w1) g]; then the mass of specific gravity bottle with distilled water was measured [(w2) g]. The mass of SAE-14 in specific gravity bottle was then recorded [(w3) g] and the specific gravity of SAE-14 was calculated using the following formula:

Specific Gravity $=\frac{(w 3-w 1) g}{(w 2-w 3) g}$

\section{Estimation of $\mathrm{pH}$}

Calibrated pH meter (Thermo-scientific STAR A214) was used to check the pH of SAE-14 [17].

Estimation of sugar content and refractive index

The refractive index and sugar content of SAE-14 were estimated by using refractometer [17].

\section{Evaluation of microbiological limits}

All the experiments were performed in accordance to the SLS standard methods [18-20]. 


\section{Estimation of aerobic count}

Using a sterile pipette, serial dilutions $\left(10^{-2}, 10^{-3}, 10^{-4}\right.$ and so on) of SAE-14 were prepared and one $\mathrm{mL}$ of each dilution was poured on the plate count agar (PCA) media. The media was allowed to solidify by inverting the dishes. The plates were incubated at $30 \pm$ $1^{\circ} \mathrm{C}$ for $72 \pm 3 \mathrm{~h}$ and the number of bacterial colonies were counted [19]. This experiment was done in triplicate.

\section{Enumeration of yeasts and moulds}

Using a sterile pipette, one $\mathrm{mL}$ of serially diluted SAE - 14 were poured on petri dishes containing $15 \mathrm{~mL}$ of Sabouraud Dextrose Agar (SDA). The media was allowed to solidify. The plates were kept inverted, incubated at $25 \pm 1{ }^{\circ} \mathrm{C}$ for 3 - 5 days and the number of colonies were counted and recorded [19].

\section{Detection of Escherichia coli}

Ten mL of serially diluted SAE-14 were poured aseptically on sterile conical flasks containing $90 \mathrm{~mL}$ of Lactose broth. The contents were mixed, incubated at $37 \pm 2{ }^{\circ} \mathrm{C}$ for $18-24 \mathrm{~h}$. One mL of this broth was taken, aseptically transferred to $10 \mathrm{~mL}$ sterile MacConkey's broth tube having Durham tube and incubated at $36 \pm 1$ ${ }^{\circ} \mathrm{C}$ for $48 \mathrm{~h}$. Presence of acid and gas in the MacConkey's broth tube indicated the presence of coliforms [18].

\section{Confirmation of coliforms}

A loopful of cultures from positive MacConkey's broth tubes were sub-cultured in tubes containing $10 \mathrm{~mL}$ of BGB broth. The tubes were incubated at $36 \pm 1^{\circ} \mathrm{C}$ for $24-48 \mathrm{~h}$ and observed for gas production [18].

\section{Examination of faecal coliforms}

A loopful of culture from positive MacConkey's broth tubes were inoculated in $10 \mathrm{~mL}$ of BGB broth prewarmed to $44 \pm 0.1^{\circ} \mathrm{C}$. The tubes were incubated at $44 \pm 0.1^{\circ} \mathrm{C}$ for 48 hours and observed for gas production [18].

\section{Detection of Salmonella}

One $\mathrm{mL}$ of lactose broth prepared at 2.4.6.3 was transferred aseptically in to $10 \mathrm{~mL}$ of Selenite-Cystine broth and incubated at $37{ }^{\circ} \mathrm{C}$ for 18 - $24 \mathrm{~h}$. A loopful of this culture was streaked on the surface of Brilliant Green Agar plates. The plates were covered, inverted, incubated at $37{ }^{\circ} \mathrm{C}$ for $20-24 \mathrm{~h}$ and observed for the any noticeable change in the colour [20].

\section{Test for stability}

Stability test was carried out in accordance with the ICH guidelines [21]. SAE-14 containing bottles were kept in three different storage conditions $\left(25^{\circ} \mathrm{C}, 60 \% \mathrm{RH} ; 30{ }^{\circ} \mathrm{C}, 65 \% \mathrm{RH}\right.$ and $40{ }^{\circ} \mathrm{C}, 75 \%$ $\mathrm{RH})$ The physico-chemical properties of SAE-14 was analyzed at three different time intervals $\left(1^{\text {st }}, 3^{\text {rd }}\right.$ and $6^{\text {th }}$ month $)$.

\section{Results}

Physicochemical evaluation

Organoleptic features of prepared SAE-14 are shown in table 2. It has characteristic color, odour and taste. Measured pH suggested that SAE-14 was acidic in nature (Table 3). Other physicochemical charters like sugar content, refractive index and specific gravity showed that the formulation was made in accordance with SLS.

\begin{tabular}{|l|c|}
\hline Parameter & Description \\
\hline Colour & Reddish brown \\
\hline Odour & Aromatic \\
\hline Taste & Astringent \\
\hline
\end{tabular}

Table 2: Organoleptic characteristics of Siddhalepa Ayur Elixir 14 Blood Purifier.

\begin{tabular}{|l|c|}
\hline \multicolumn{1}{|c|}{ Parameter } & Observed value \\
\hline $\mathrm{pH}$ & $3.29 \pm 0.01$ \\
\hline Specific gravity & $1.03 \pm 0.01$ \\
\hline Alcohol $(\% \mathrm{w} / \mathrm{w})$ & 8.32 \\
\hline Sugar content \% & $27.21 \pm 0.02$ \\
\hline Refractive index & $1.34 \pm 0.03$ \\
\hline
\end{tabular}

Table 3: Physio-chemical properties of Siddhalepa Ayur Elixir 14 Blood Purifier.

\section{Microbiological analysis}

The microbial limits or lack of important microbial pathogens in SAE-14 is shown in table 4. As measures of microbial performance were used the total aerobic microbial count and the total yeast and mold count (presented as colony-forming units per $\mathrm{ml} \mathrm{CFU} \mathrm{/} \mathrm{ml)}$ the absence of Salmonellae, Esherichia coli and Gram-negative bacterial species. It also confirmed the quality of raw materials.

\begin{tabular}{|l|c|}
\hline \multicolumn{1}{|c|}{ Parameter } & Microbial count \\
\hline Aerobic plate count $(\mathrm{cfu} / \mathrm{mL})$ & $3.7 \times 10^{3}$ \\
\hline Yeast/mold $(\mathrm{cfu} / \mathrm{mL})$ & $3.1 \times 10^{2}$ \\
\hline Detection of coliform & Absent \\
\hline Detection of Salmonella & Absent \\
\hline
\end{tabular}

Table 4: Average microbiological counts of Siddhalepa Ayur Elixir 14 Blood Purifier.

\section{Effects in stability}

Stability test results are shown in Table 5 and SAE-14 can be stored for six months at different selected storage. 


\begin{tabular}{|c|c|c|c|c|c|c|c|c|c|c|c|c|c|c|c|c|c|c|}
\hline \multirow{3}{*}{ Time } & \multicolumn{18}{|c|}{ Description, organoleptic and physiochemical properties at different storage conditions } \\
\hline & \multicolumn{6}{|c|}{ Zone-I, $25^{\circ} \mathrm{C} / 60 \% \mathrm{RH}$} & \multicolumn{6}{|c|}{ Zone-II, $30{ }^{\circ} \mathrm{C} / 65 \% \mathrm{RH}$} & \multicolumn{6}{|c|}{ Zone-III, $40^{\circ} \mathrm{C} / 75 \% \mathrm{RH}$} \\
\hline & $\frac{\vdots}{0}$ & $\frac{\Xi}{\bar{z}}$ & 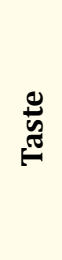 & T: & 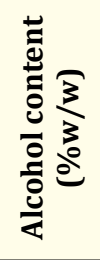 & 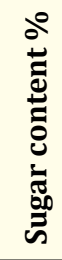 & $\frac{\grave{0}}{0}$ & $\frac{\bar{\Xi}}{0}$ & 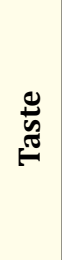 & $\underline{I}$ & 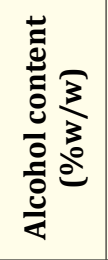 & 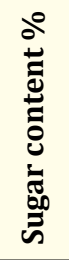 & $\frac{\Xi}{0}$ & $\begin{array}{l}\bar{z} \\
\overline{0}\end{array}$ & 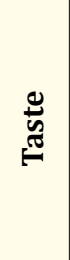 & 公 & 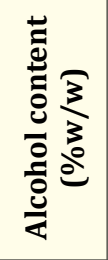 & 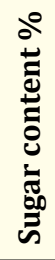 \\
\hline 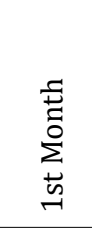 & 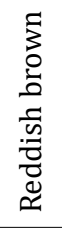 & 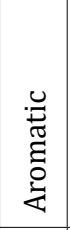 & 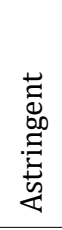 & $\begin{array}{c}\tau \\
\delta \\
0 \\
+ \\
0 \\
\circ \\
\dot{+}\end{array}$ & $\underset{\substack{\infty \\
\stackrel{\infty}{\infty}}}{ }$ & $\begin{array}{l}\text { Oे } \\
0 \\
+ \\
+ \\
\text { Ln } \\
\stackrel{+}{N}\end{array}$ & 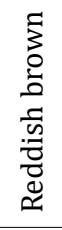 & 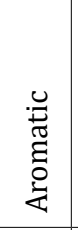 & 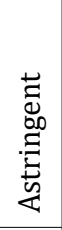 & $\begin{array}{l}\vec{b} \\
\dot{0} \\
\dot{0} \\
\dot{0} \\
\dot{m}\end{array}$ & $\begin{array}{l}\stackrel{\circ}{a} \\
\stackrel{\infty}{0}\end{array}$ & 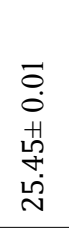 & 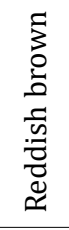 & 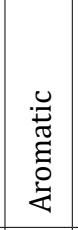 & 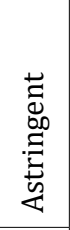 & $\begin{array}{l}\vec{\sigma} \\
0 \\
+ \\
0 \\
\dot{+}\end{array}$ & $\begin{array}{l}\stackrel{0}{0} \\
\infty\end{array}$ & 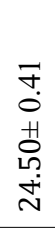 \\
\hline $\begin{array}{l}\text { 志 } \\
\sum_{0}^{0} \\
\text { D. }\end{array}$ & 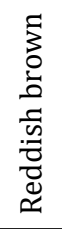 & 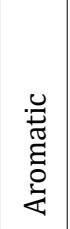 & 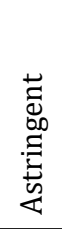 & $\begin{array}{l}\overrightarrow{0} \\
0 \\
+ \\
\stackrel{+}{N} \\
\dot{m}\end{array}$ & $\stackrel{\sigma}{\sigma}$ & 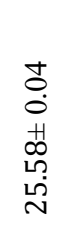 & 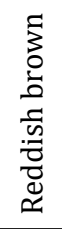 & 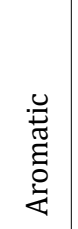 & 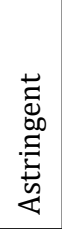 & $\begin{array}{l}2 \\
\delta \\
0 \\
\dot{0} \\
\dot{0} \\
\dot{+}\end{array}$ & $\begin{array}{l}\stackrel{0}{0} \\
\infty\end{array}$ & $\begin{array}{l}= \\
\overline{0} \\
+ \\
0 \\
+ \\
\infty \\
\text { i }\end{array}$ & 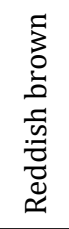 & 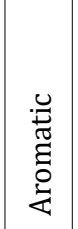 & 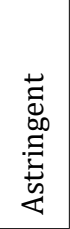 & $\begin{array}{l} \\
\stackrel{0}{0} \\
+1 \\
+1 \\
\stackrel{1}{+} \\
+\end{array}$ & $\underset{\infty}{\stackrel{N}{\infty}}$ & 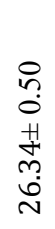 \\
\hline 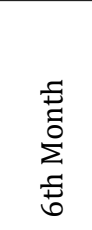 & 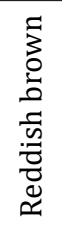 & 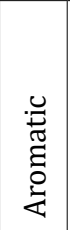 & 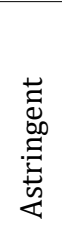 & 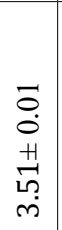 & $\stackrel{?}{\stackrel{R}{\wedge}}$ & \begin{tabular}{l}
$n$ \\
0 \\
0 \\
$H$ \\
Ln \\
\multirow{+}{0}{} \\
$\stackrel{0}{0}$
\end{tabular} & 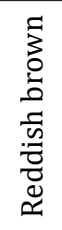 & 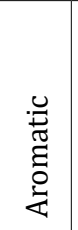 & 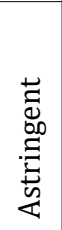 & 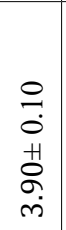 & $\underset{\infty}{\stackrel{\sim}{N}}$ & 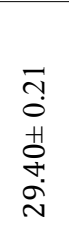 & 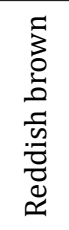 & 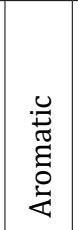 & 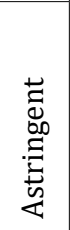 & $\begin{array}{l}= \\
= \\
0 \\
+ \\
\stackrel{+}{+} \\
+\end{array}$ & $\underset{\infty}{\stackrel{0}{1}}$ & 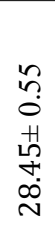 \\
\hline
\end{tabular}

Table 5: Stability data of the Siddhalepa Ayur Elixir 14 Blood Purifier.

\section{Discussion}

For their potential application in the biomedical system, standardization of natural products is more important. By using existing methods and applying correct guidelines and principles, the WHO has emphasized the need to ensure quality control for herbal products [22]. In that contest this communication standardized the physicochemical parameters of SAE -14 .

Organoleptic characteristics of SAE-14 revealed that it is palatable with fine aroma. The $\mathrm{pH}$ showed that SAE-14 had weak acidic properties. Since autogenic alcohol acts as a preservative and increases formulation stability; addition of preservatives is unnecessary.

Absence of specified microorganisms like Salmonella, Esherichia coli in SAE-14 suggested that SAE-14 is safe for human consumption. The stability of the SAE-14 results are reproducible, even on SAE-14 bottle that had been stored for six months at different storage conditions.

Formulation of decoction is the step of primary significance in the manufacturing of arishta formulations. Constant mild heating during the preparation of decoction facilitates extraction of watersoluble components of the herbal drug. But excessive heating re- sults in charring of plant drug. Added Embelia ribes fruits and sugar are source of nutrient and also initiator of fermentation process. Specially Embelica ribes enhance the digestion in intestine [23]. Temperature at fermentation area can affect duration and extent of fermentation process hence season of fermentation is important for production of arishta by traditional method.

Previously Kroes and co-workers [5] showed the immunomodulatory effect of Nimba arishta. Anti-inflammatory and antimicrobial effect of Azadirachta indica, the main ingredient of this SAE14 were also reported in the literature; it may contribute SAE-14's therapeutic value. Neem is considered as one of the most powerful blood purifier and antidote in Ayurveda [24]. It is an effective therapy for skin infections, rashes and pimples due to its powers of internal cleansing [25]. This study analyzed the quality and specifications of SAE-14 according the international standards. Biological activities and pathway studies need to be evaluated to get more knowledge on the application of SAE- 14 .

\section{Conclusion}

This study standardized a traditional ayurvedic arishata formulation SAE-14 according to the international standards. Traditional formulations are losing their value in international market. Alcohol percentage, $\mathrm{pH}$, sugar content, refractive index, specific gravity and 
microbial limits can be considered as the basic tools for the quality control measures of arishtas to improve their acceptance. Further, studies on their safety and efficacy will improve their acceptance.

\section{Acknowledgments}

We thank Hettigoda Industries (Pvt) Ltd, 33/3, Sri Dharmarama Road, Ratmalana, Sri Lanka. for providing facilities and financial assistance.

\section{Bibliography}

1. PK Mukherjee and A Wahile. "Integrated approach towards drug development from Ayurveda and other Indian systems of medicine". Journal of Ethnopharmacology 103 (2006): 25-35.

2. Thatte Urmila M and Sharadini A Dahanukar. "Ayurveda and contemporary scientific thought". Trends in Pharmacological Sciences 7 (1986): 247-251.

3. Bouldin Alicia S., et al. "Pharmacy and herbal medicine in the US”. Social Science and Medicine 49.2 (1999): 279-289.

4. Sekar S and S Mariappan. "Traditionally fermented biomedicines, arishtas and asavas from Ayurveda". (2008).

5. Kroes BH., et al. "Impact of the preparation process on immunomodulatory activities of the ayurvedic drug Nimba arishta". Phytotherapy Research 7.1 (1993): 35-40.

6. Mishra AK., et al. "Asava and aristha: An ayurvedic medicineAn overview". International Journal of Pharmaceutical and Biological Archive 1.1 (2010): 24-30.

7. Mulay Sushruta and Anubha Khale. "Asavarishtas through improved fermentation technology". International Journal of Pharmaceutical Sciences and Research 2.6 (2011): 1421.

8. Kalaiselvan V., et al. "Quality assessment of different marketed brands of Dasamoolaristam, an Ayurvedic formulation". International Journal of Ayurveda Research 1.1 (2010): 10.

9. Middelkoop Teunis B and Rudi P Labadie. "Evaluation of Asoka Aristha an indigenous medicine in Sri Lanka”. Journal of Ethnopharmacology 8.3 (1983): 313-320.

10. Namjoshi Anant. "Ayurvedic pharmacopoeia and drug standardisation". Realms of ayurveda. Arnold-Heinemann, New Delhi (1979): 217-273.

11. Sharma PV. "Introduction to Dravyaguna (Indian Pharmacology) Varanasi”. India: Chaukhambha Orientalia (1976).

12. Sharma RK and Bhagwan-das V Charaka Samhita. "The Chaukhamba Sanskrit Series Office, Varanasi” India, 397 (1976): 439-444.

13. Van der Nat JM., et al. "Immunomodulatory activity of an aqueous extract of Azadirachta indica stem bark". Journal of Ethnopharmacology 19.2 (1987): 125-131.
14. Anonymous Pharmacopoeia Ayurvedic. "Department of Ayurveda, Colombo Sri Lanka”. Vol I pt 1 (1979).

15. Kroes BH., et al. "Investigations on Nimba arishta, an Ayurvedic Drug Obtained by Fermentation with Immuno-Modulating Properties". Planta Medica 55.07 (1989): 651-652.

16. WHO. "Quality control methods for medicinal plant materials". (1998).

17. Anonymous, Pharmacopoeia, British. New Delhi: Controller of Publication, Government of India, Ministry of Health and Family Welfare 1 (1996): 736

18. SLS 516 Part 3: (TM-LA-MB-03) Microbiology Testing on Products Categories of Food and Agricultural Products and Water based on SLS and ISO Test Methods (1982).

19. SLS 516 Part 1: (TM-LA-MB-01) Microbiology Testing on Products Categories of Food and Agricultural Products and Water based on SLS and ISO Test Methods (1991).

20. SLS 516 Part 2: (TM-LA-MB-02) Microbiology Testing on Products Categories of Food and Agricultural Products and Water based on SLS and ISO Test Methods (1992).

21. ICH Guideline ICH Harmonised Tripartite. "Stability testing of new drug substances and products". Q1A (R2), current step 4 (2003): 1-24.

22. S Sylvester Darvin., et al. "Standardization of Natural Products and Drugs". Acta Scientific Pharmaceutical Sciences 3.2 (2019): 19-20.

23. Bharat Lal and Neeraj Mishra. "Importance of Embelia Ribes: An Update" Journal of Pharmaceutical Sciences and Research 4.10 (2013): 3823-3838.

24. Alzohairy Mohammad A. "Therapeutics role of Azadirachta indica (Neem) and their active constituents in diseases prevention and treatment". Evidence-Based Complementary and Alternative Medicine (2016).

25. Al-Hashemi., et al. "Biological activities of different neem leaf crude extracts used locally in Ayurvedic medicine". Pacific Science Review A: Natural Science and Engineering 18.2 (2016): 128-131.

Volume 3 Issue 12 December 2019 (C) All rights are reserved by Darvin S S., et al. 